Research

Open Access

\title{
Dietary Supplementation of Fructooligosaccharides Reduces Hepatic Steatosis Associated with Insulin Resistance in Obese Zucker Rats
}

\section{Lydia Kaume, William Gilbert, Vidya Gadang, *Latha Devareddy}

Food Science Department, University of Arkansas, 2650 N. Young Avenue, Fayetteville AR, 72704, USA

*Corresponding author: Latha Devareddy, PhD, Department of Food Science, University of Arkansas, Fayetteville, AR, USA

Running title: Fructooligosaccharides and Obesity

Submission date: February 27, 2011; Acceptance date: May 23, 2011; Publication date: May 24, 2011

\section{$\underline{\text { Abstract }}$}

Background: One in five adults in the United States is obese as defined by a body mass index of $30 \mathrm{~kg} / \mathrm{m}^{2}$. Obesity is associated with metabolic syndrome, a combination of medical conditions including cardiovascular disease, type 2 diabetes, hypertension, hypercholesterolemia, and hypertriglyceridemia. These conditions present challenges to the medical care system and require a multifaceted approach through a variety of interventions. This study investigated the effects of fructooligosaccharides (FOS) at the level of $5 \%(\mathrm{w} / \mathrm{w})$ in alleviating the complications associated with metabolic syndrome.

Methods: The study was carried out using thirty-six, three-month old female lean and obese Zucker rats housed in an environmentally controlled laboratory. The Zucker rats were divided into three groups $(\mathrm{N}=12)$ : Lean (L-CTRL) and obese controls (O-CTRL) and obese-FOS (OFOS). The controls received AIN-93M purified rodent diet and the animals in the O-FOS group were fed AIN-93M diet modified to contain 5.0\% FOS (w/w). After 100 days of treatment, the rats were fasted for 12 hours and sacrificed. Tissue and organs of interest, and blood were collected for analysis. Serum concentrations of the following were determined: glucose, glycosylated hemoglobin (HbA1c), total cholesterol (TC), low-density lipoprotein-cholesterol (LDL-C), high-density lipoprotein-cholesterol (HDL-C), triglycerides (TG), and insulin. Gravimetric quantification of liver lipids was performed and peroxisome proliferator-activated receptor- $\gamma($ PPAR- $\gamma)$ gene expression was determined in white adipose tissue by qRT-PCR. 
Results: No significant differences were observed in the serum lipids, fasting blood glucose, HbA1c and PPAR- $\gamma$ gene expression in white adipose tissue of O-FOS group compared to OCTRL group. FOS supplementation significantly lowered the percent total liver lipids by $12 \%$ with a subsequent reduction in the liver weights compared to O-CTRL rats. Serum insulin concentrations were lowered 3.6 fold in O-FOS group compared to O-CTRL $(\mathrm{P}<0.05)$.

Conclusion: Based on these findings we conclude that dietary supplementation of 5\% FOS (w/w) may reduce hepatic steatosis and the risk for non-alcoholic fatty liver disease (NAFLD) associated with insulin resistance without changes in blood lipids and glucose levels.

Key words: Dietary fiber, Fructooligosaccharide, Hepatosteatosis, Liver lipids, Non-alcoholic fatty liver disease (NAFLD), Zucker.

\section{Background:}

The prevalence of obesity in both adults and children has doubled in the past two decades and is now recognized as a global pandemic affecting both developed and developing nations [1]. One in five adults in the United States is obese as defined by a body mass index of $30 \mathrm{~kg} / \mathrm{m}^{2}$ [2] Obesity is associated with several chronic diseases such as cardiovascular disease (CVD), type 2 diabetes, hypertension, hypercholesterolemia, and hypertriglyceridemia [3]. These myriad of conditions present a major challenge to the medical care system and requires a multifaceted approach through a variety of interventions. Pharmacological approaches use prescription drugs such as those that may inhibit cholesterol synthesis or regulate hormones such as insulin [4] and important nuclear receptors such as peroxisome proliferator-activated receptor- $\gamma$ (PPAR- $\gamma$ ) [5]. Currently, there is an increased search for safe and effective alternatives to pharmacological interventions including increased physical activity integrated with changes in the diet. Dietary interventions such as low-fat diets, calorie restricted diets, and dietary fiber supplementations are strategies focused on preventing obesity related risk factors. In particular, dietary fiber modulates insulin secretion and regulates circulating insulin levels, which play a critical role in glucose homeostasis and management of diabetes type 2 [6]. In addition, there is evidence that dietary fiber incorporated in healthy diets increases satiety value, provides bulk to stool, decreases intestinal transit time, and reduces the risk for colon cancer [7]. Short chain fructooligosccharide (FOS) is a soluble fiber, inulin-like fructan with prebiotic properties and is low caloric value, approximated as 0-3 Kcal/g of sugar substitute [8]. FOS are oligomers of fructose composed of short chains of approximately 3-6 units of fructose units bound by $\beta-(2-1)$ linkages attached to a terminal glucose unit [9]. They are found in many edible plants such as onions, artichokes, chicory, asparagus, wheat, and many other plants rich in inulin [9].

Several studies have used dietary FOS at the level of 5-10\% to investigate its effect on gastrointestinal benefits, weight and fat mass loss mechanisms, and lipid metabolism [10-13]. Although 10\% FOS was reported to have undesirable effects such as decreased short chain fatty 
acid (SCFA) concentration, and excessive enlargement of the caecum tissue in rat models [14], the dose has been effective in lowering plasma glucose and reducing triglyceride concentration in liver[15,16]. However, $5 \%$ of soluble dietary fiber is a feasible amount of daily intake since FOS is found in small amounts in natural food sources [9] and supplementation of 5\% FOS in human diets has been physiologically effective in improving glucose control, enhancing satiety, nutrient absorption and improving fecal bulking [9]. However findings on the potential lipid lowering effects of FOS are both limited and inconsistent in obese states in both animal models and humans $[13,17,18]$. Therefore this study investigates the effects of supplementing 5\% FOS $(w / w)$ in improving serum and liver lipid profiles, serum glucose and PPAR- $\gamma$ gene expression in white adipose tissue of $f a / f a$ Zucker rats.

\section{Methods}

\section{Animals and diets}

Thirty-six, three-month old female lean and obese Zucker rats (Harlan, Indianapolis, IN) were housed in an environmentally controlled laboratory. The animals were housed in plastic cages in pairs at a room temperature of $22 \pm 1{ }^{\circ} \mathrm{C}$ under a 12-h light-dark cycle. The study was carried out in accordance with the regulations for humane treatment of animals set by the University of Arkansas Institutional Animal Care and Use Committee. The rats were pair-fed to the mean intake of the L-CTRL group and the food intake was measured three times a week. Pair-feeding was necessary to match the macronutrient intake of all the groups. Food intake was monitored three times a week and the rats had free access to deionized water. Animals were weighed once a week, and were on treatment for 100 days.

The Zucker rats were divided into three groups $(\mathrm{N}=12)$. The rats in the lean and obese control groups were fed AIN-93M purified rodent diet. The groups were as follows: lean + control diet (L-CTRL), obese + control diet (O-CTRL) and obese $+5 \%$ FOS (w/w) (O-FOS). The rats in FOS group received a purified diet modified to contain 5\% of short chain FOS (w/w). FOS P-95 provided by NutraFlora ${ }^{\circledR}$ contains more than 95 percent fructooligosaccharides [comprised of 50\% nystose (GF3), 35\% kestose (GF2), and 10\% fructosynlnystose (GF4)], less than $5 \%$ glucose+fructose+sucrose, less than $5 \%$ moisture, and less than $0.1 \%$ ash (NutraFlora ${ }^{\circledR}$ GTC Nutrition, Golden CO). Diet composition of the treatment and control groups is shown in Table 1.

\section{Animal necropsy and sample processing}

After 100 days of treatment, the rats were fasted for 12 hours before being anesthetized with a mixture of ketamine and xylazine, $70 \mathrm{mg}$ and $3 \mathrm{mg} / \mathrm{kg}$ body weight, respectively, and sacrificed by exsanguination via cardiac puncture. Tissue and organs of interest were collected and flash frozen before being stored at $-80^{\circ} \mathrm{C}$. A small aliquot of whole blood was stored in a microtube containing EDTA for later determination of $\mathrm{HbAlc}$, while the remainder of the blood collected 
from the animal during sacrifice was centrifuged at $3000 \mathrm{xg}$ for 20 minutes at $4{ }^{\circ} \mathrm{C}$ to separate serum from whole blood. Aliquots of serum were stored at $-80^{\circ} \mathrm{C}$ until further analysis.

Table 1: Diet composition of the control and FOS diet fed to Zucker rats

\begin{tabular}{|c|c|c|}
\hline Ingredients $^{\mathrm{a}}(\mathrm{g} / 1000 \mathrm{~g})$ & CTRL $^{\mathrm{c}}$ & FOS $^{d}$ \\
\hline Total energy ${ }^{\mathrm{b}}, \mathrm{kcal}$ & 4004 & 4004 \\
\hline Cornstarch & 436 & 436 \\
\hline Maltodextrin & 155 & 155 \\
\hline Sucrose & 100 & 50 \\
\hline FOS & 0 & 50 \\
\hline Casein & 170 & 170 \\
\hline Soybean oil & 40 & 40 \\
\hline Cellulose & 50 & 50 \\
\hline AIN-93-VX vitamin mix & 10 & 10 \\
\hline AIN-93M-MX mineral mix & 35 & 35 \\
\hline $\mathrm{TBHQ}^{\mathrm{f}}$ & 0.008 & 0.008 \\
\hline L-Cysteine & 1.8 & 1.8 \\
\hline Choline bitartrate & 2.5 & 2.5 \\
\hline
\end{tabular}

${ }^{a}$ Diet ingredients were purchased from Harlan Laboratories Inc., (Indianapolis, IN) unless otherwise noted.

${ }^{\mathrm{b}}$ The estimate of caloric content was based on the standard physiological fuel values for carbohydrate, fat, and protein of 4, 9 and 4, respectively.

${ }^{\mathrm{c}} \mathrm{CTRL}=$ Control Diet

${ }^{\mathrm{d}} \mathrm{FOS}=$ FOS diet

${ }^{\mathrm{f}} \mathrm{TBHQ}=$ tertiary-butylhydroquinone, an antioxidant required to prevent lipid oxidation Purchased from ACROS Organics (New Jersey, USA)

\section{Serum biochemistry}

An ACE Alera clinical chemistry system (Alfa Wassermann diagnostic technologies, West Caldwell, NJ) calibrated against manufacturer standards and subjected to regular quality control checks was used to determine the serum concentrations of the following: glucose, glycosylated hemoglobin (HbA1c), total cholesterol (TC), low-density lipoprotein-cholesterol (LDL-C), high- 
density lipoprotein-cholesterol (HDL-C), and triglycerides (TG). Commercially available kits from Alfa Wassermann diagnostic technologies (West Caldwell, NJ) were used following manufactures instructions.

\section{Liver lipids and cholesterol}

Liver lipids were extracted and gravimetric quantification was performed using Folch's method [19] of lipid extraction. One gram of liver was homogenized in a 20-fold volume of 2:1 chloroform-methanol (v/v) mixture. Following homogenization, $0.58 \% \mathrm{NaCl}$ solution was added to achieve separation of the phases and centrifuged for $20 \mathrm{~min}$ at $500 \mathrm{xg}$. Supernatant was discarded and the organic phase was filtered and washed with chloroform through fat free filter paper (3.2 cm Whatman, Whatman International Ltd, Maidstone, England). The filtered organic phase containing the tissue lipids was then transferred to a scintillation vial and weighed. Liver total cholesterol was determined using the method described by Searcy and Bergquist [20].

\section{Insulin}

Serum insulin was quantified using a commercially available enzyme linked immune assays (ELISA, Alpco Immunoassays, Salem NH). Serum was thawed on ice before analysis. A 96-well plate in the kit was prepared per manufacturer's instructions to include standards, appropriate controls, and samples. Absorbance was measured using a BioTek ELx808 microplate reader (Winooski, VT) with a BioTek Gen5 data analysis software (Winooski, VT).

\section{PPAR expression in white adipose tissue by $q R T-P C R$}

RNA was extracted from approximately $100 \mathrm{mg}$ of visceral/abdominal white adipose tissue by TRIzol Reagent method, by using RNeasy Lipid Tissue Mini Kit (Qiagen Inc. Valencia, CA) following the supplier's instructions. RNA concentration was determined by absorbance at 260 $\mathrm{nm}$ by NanoDrop (Thermo Fisher Scientific Inc.,Wilmington, DE) and $500 \mathrm{ng} / \mathrm{sample}$ was used to synthesize cDNA. PCR was performed using a solution containing primer pairs from gene of interest and the housekeeping gene. The PPAR $\gamma$ and $\beta$-actin cDNA was synthesized with oligo (dT) primers (PPAR $\gamma$ : Sense 5'-CACAAGAGCTGACCCAATGGTTGCTG-3', antisense 5'GCAGATCAGCAGACTCTGGGTTC-3'， $\beta$-actin: Sense 5'-TCTACAATGAGCTGCGTGTG-3' antisense 5'GGTCAGGATCTTCATGAGGT-3' and reverse transcriptase according to the instructions of the supplier (Qiagen Inc. Valencia, CA). All the primer sets were synthesized by Integrated DNA technologies (Coralville, IA). Real time PCR was performed on the Mastercycler ep realplex real-time PCR system (Eppendorf Inc., Hauppauge, NY). The initial denaturation cycle was performed at $95^{\circ} \mathrm{C}$ for $5 \mathrm{~min}$. All subsequent denaturation and annealing cycles were repeated 45 times at $95^{\circ} \mathrm{C}$ for $15 \mathrm{~s}$ and $60^{\circ} \mathrm{C}\left(55^{\circ} \mathrm{C}\right.$ annealing for reference gene $\beta$ actin) for $45 \mathrm{~s}$, respectively.

\section{Statistical analysis}


The data analysis involved computation of means and standard error of mean using JMP 8 (2009 SAS Institute Inc. Cary, NC). Analysis of variance (ANOVA) was performed to determine whether there were statistically significant $(\mathrm{P}<0.05)$ differences among the groups. When data indicated overall significance, Fisher's Least Significant Difference test was used to detect differences between means $(\mathrm{P}<0.05)$.

\section{Results:}

Body weights, organ weights, and food intake

The effects of treatment on body weights, organ weights, and average food intake are shown in Table 2.

Table 2: Effects of fructooligosaccharide supplementation on the body and organ weights of Zucker rats

\begin{tabular}{llll}
\hline & L-CTRL & O-CTRL & O-FOS \\
\hline $\begin{array}{l}\text { Average food } \\
\text { consumption (g) }\end{array}$ & $16.24 \pm 0.75^{\mathrm{b}}$ & $17.88 \pm 0.49^{\mathrm{a}}$ & $18.35 \pm 0.39^{\mathrm{a}}$ \\
& & & \\
Body weight (g) & & & \\
$\quad$ Initial & $179 \pm 6^{\mathrm{b}}$ & $330 \pm 6^{\mathrm{a}}$ & $331 \pm 6^{\mathrm{a}}$ \\
$\quad$ Final & $300 \pm 6^{\mathrm{b}}$ & $538 \pm 6^{\mathrm{a}}$ & $550 \pm 7^{\mathrm{a}}$ \\
$\begin{array}{l}\text { Organ weights (g) } \\
\text { Liver }\end{array}$ & $8.57 \pm 1.41^{\mathrm{c}}$ & $31.34 \pm 1.4^{\mathrm{a}}$ & $25.68 \pm 1.4^{\mathrm{b}}$ \\
Spleen & $0.46 \pm 0.02^{\mathrm{b}}$ & $0.64 \pm 0.02^{\mathrm{a}}$ & $0.64 \pm 0.02^{\mathrm{a}}$ \\
& & & \\
\hline
\end{tabular}

Data represents the mean \pm S.E.M. Values in a row not sharing the same letter are significantly different $(p$ < 0.05). L-CTRL: Lean + control, O-CTRL: Obese + control O-FOS: obese + fructooligosaccharides.

The obese rats were pair-fed to the mean food intake of the lean controls, and there was no difference in food intake between the two obese groups. There was no significant difference in final body weights and final spleen weights when O-FOS group was compared to O-CTRL group. However, we observed that liver weights were significantly different between the three experimental groups with livers from the obese groups being heavier than the lean rat livers $(\mathrm{P}<$ $0.05)$. FOS supplementation was effective in lowering liver weights by $18 \%$ when compared to obese control thus reducing hepatomegaly.

\section{Serum and liver lipids}

The effects of treatment on serum and liver parameters are shown in Table 3. There were no significant differences in the TC, HDL-C, LDL-C, and triglycerides levels between the O- 
CTRL and O-FOS groups. FOS supplementation lowered the total liver lipid concentration by $12 \%$ compared to the O-CTRL group ( $<<0.05)$, suggesting that the FOS diet was effective in lowering hepatic steatosis. There was no significant difference in the liver cholesterol levels between the O-CTRL and O-FOS groups. As expected the serum and liver lipid levels of the LCTRL group remained lower than those of the other experimental groups.

Table 3: Effect of FOS supplementation on serum lipid profiles and liver lipid profiles of genetically obese Zucker rats

\begin{tabular}{rlll}
\hline Parameter & L-CTRL & O-CTRL & O-FOS \\
\hline Blood Lipids (mmol/L) & & & \\
Triglycerides & $0.96 \pm 0.37^{\mathrm{a}}$ & $1.81 \pm 0.26^{\mathrm{ab}}$ & $2.04 \pm 0.30^{\mathrm{b}}$ \\
Total Cholesterol & $2.15 \pm 2.04^{\mathrm{a}}$ & $12.43 \pm 1.39^{\mathrm{b}}$ & $11.66 \pm 0.68^{\mathrm{b}}$ \\
HDL-C & $0.56 \pm 0.16^{\mathrm{a}}$ & $1.71 \pm 0.11^{\mathrm{b}}$ & $1.73 \pm 0.13^{\mathrm{b}}$ \\
LDL-C & $0.13 \pm 0.23^{\mathrm{a}}$ & $1.29 \pm 0.16^{\mathrm{b}}$ & $1.13 \pm 0.18^{\mathrm{b}}$ \\
Liver Lipids Profile & & & \\
\% Liver Lipids & $9.69 \pm 0.00^{\mathrm{a}}$ & $32.93 \pm 0.00^{\mathrm{c}}$ & $28.85 \pm 0.00^{\mathrm{b}}$ \\
\% Liver Cholesterol & $0.22 \pm 0.00^{\mathrm{a}}$ & $0.24 \pm 0.00^{\mathrm{b}}$ & $0.23 \pm 0.00^{\mathrm{ab}}$ \\
\hline
\end{tabular}

Data represents the mean \pm S.E.M. Values in a row not sharing the same letter are significantly different ( $\mathrm{p}<0.05)$. L-CTRL: Lean + control, O-CTRL: Obese + control O-FOS: obese + fructooligosaccharides.

\section{Serum glucose and insulin}

The effects of dietary treatment of FOS on circulating insulin, glucose and HbA1c concentrations are shown in Table 4.

Table 4: Effects of fructooligosaccharide supplementation on serum insulin, glucose and glycated hemoglobin (HbA1c) levels in obese Zucker rats.

\begin{tabular}{llll}
\hline Parameter & L-CTRL & O-CTRL & O-FOS \\
\hline Insulin (ng/mL) & $0.22 \pm 0.16^{\mathrm{b}}$ & $1.47 \pm 0.17^{\mathrm{a}}$ & $0.41 \pm 0.16^{\mathrm{b}}$ \\
Glucose $(\mathrm{mmol} / \mathrm{L})$ & $13.58 \pm 1.96^{\mathrm{b}}$ & $25.18 \pm 1.33^{\mathrm{a}}$ & $26.30 \pm 1.51^{\mathrm{a}}$ \\
HbA1c $(\%)$ & $3.51 \pm 0.11$ & $3.71 \pm 0.11$ & $4.12 \pm 0.11$ \\
& & & \\
\hline
\end{tabular}

Data represents the mean \pm S.E.M. Values in a row sharing by same letter are significantly different $(\mathrm{p}<$ 0.05) L-CTRL: Lean + control, O-CTRL: Obese + control, O-FOS: obese + fructooligosaccharides. 
The treatment group showed no significant difference in the glucose concentration levels compared to the O-CTRL. L-CTRL group showed significantly lower blood glucose levels compared to the obese groups ( $\mathrm{P}<0.05$ ). Levels of HbA1c in the O-FOS group were higher than O-CTRL group albeit insignificant. Serum insulin levels of O-FOS group were 3.6 fold lower than the O-CTRL, and not significantly different from those of L-CTRL group $(\mathrm{P}<0.05)$.

PPAR gene expression in white adipose tissue

This study also explored the effects of FOS on PPAR- $\gamma$ gene expression in white adipose tissue by RT-PCR (Figure1). PPAR- $\gamma$ is a class of nuclear receptors which regulates lipid and lipoprotein metabolism, energy homeostasis, and anti-inflammation factors. This study showed no significant difference in the relative gene expression level of PPAR- $\gamma$ among the three groups.

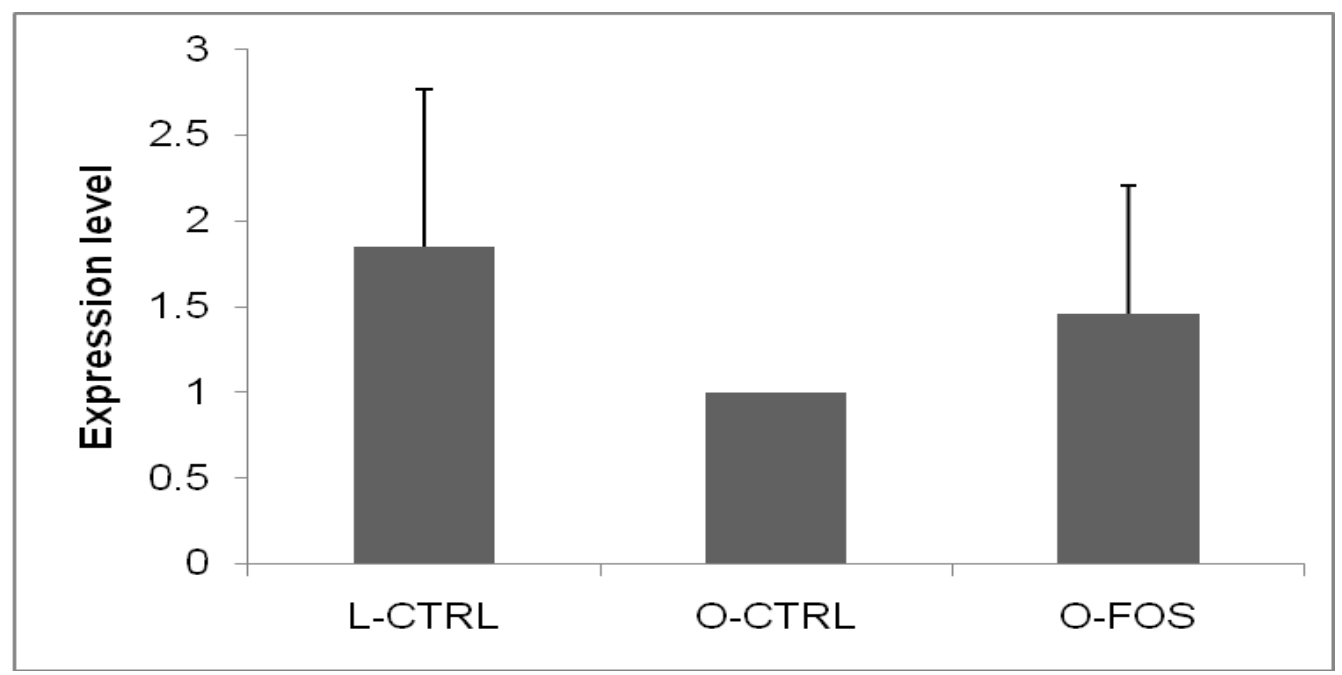

Figure 1: Expression of PPAR- $\gamma$ in Zucker rat abdominal white adipose tissue treated with fructooligosaccharide compared to the lean control by RT-PCR. The experiment was normalized to $\beta$ actin as an internal control and results were reported as expression ratio of the obese control value. Values are means, standard errors represented by vertical bars.

\section{Discussion:}

Studies show that FOS supplementation confers prebiotic effects [12], and promotes gut maturation and integrity by promoting the growth of beneficial colonic microflora, especially bifidobacteria [21, 22]. Furthermore, FOS has shown to increase satiety value [9], and improve nutrient absorption (mainly minerals iron, magnesium, and calcium), because the non-digestible starch decreases intestinal transit time [23, 24]. In fact, results on dose dependent effects show that feeding rats a diet containing 10 and $20 \%$ oligofructose for 6 weeks shortens mouth to anus transit time by 25 to $50 \%$ respectively [25]. Other beneficial effects include weight loss and anti-diabetic effects via glucose regulation [26], and modulating liver and plasma lipid profiles in both humans and animals $[15,27,28]$. 
In this study, $5 \%$ FOS (w/w) supplementation had no effect on the final body weights of the obese rats. Daubioul and colleagues [29] in a similar experiment observed less energy consumption and a 10\% reduction in body weight in FOS fed rats when compared to the controls. In their study, $10 \%(\mathrm{w} / \mathrm{w})$ FOS diet was used in the same rat model for a treatment period of 10 weeks. Hence, FOS at the level of $10 \%$ and not $5 \%$ may be more effective in reducing body weights in the obese Zucker rats.

Although the exact mechanism remains unclear, the pathogenesis of fatty liver (steatosis) is multifactorial, and it has been suggested that the presence of insulin resistance (IR) is an essential requirement for the accumulation of hepatocellular fat [30, 31]. IR is the abnormally low response of organs and tissues o the action of insulin resulting in hyperinsulinemia and consequently hyperglycemia [3]. It is postulated that IR is as a result of the combination of elevated plasma concentrations of glucose and fatty acids which leads to increased hepatic fatty acid synthesis, impaired $\beta$-oxidation, and hepatic steatosis [30, 32]. In fact, Samuel et al., presents evidence of the cellular mechanism in which hepatic fat accumulation leads to hepatic IR in rat model of non-alcoholic fatty liver disease [33]. Other than IR, steatosis may result from alterations in the uptake, synthesis, degradation or secretory pathways of hepatic lipid metabolism [33].

This study demonstrated that FOS lowered percent liver lipids and decreased three fold in the insulin levels in obese rats. Our findings suggest that FOS may be protective against hepatic steatosis, consequently reducing the risk for non-alcoholic fatty liver disease (NAFLD) associated with IR and excess intra-hepatic triglyceride content [34] found in obese states. NAFLD is a major risk factor for multi-organ disease complex and correlates directly with IR in both muscle and liver tissues [34]. Our results are similar to those of Daubioul et al [29], who performed histological examination of livers of obese Zucker rats and found a reduction in fat cells in livers of rats fed 10\% FOS (w/w) [29]. Currently, evidence suggests that FOS lowers liver lipids via short chain fatty acids inhibition of key lipogenic enzymes including fatty acid synthase (FAS) which catalyzes the synthesis of long-chain fatty acids [35]. Propionate may inhibit the incorporation of acetate into fatty acids by suppressing FAS activity [3]. Moreover, FAS is known to increase with high-carbohydrate/fat-free feeding and decrease in fasting states [36]. The nutritional glycolytic metabolites are reported to not only increase mRNA stability but also increase the transcriptional rate, mRNA concentration and enzyme induction of FAS. Modifying our diet with FOS reduced the sucrose by 50\% compared to the control diet may have influenced FAS activity. We propose this is probable because Agheli and colleagues compared a sucrose-rich diet to a sucrose-FOS diet in insulin resistant Sprague-Dawley rats, and observed lowered fatty acid synthase (FAS) activity in the liver and $11 \%$ lower liver weights than controls. Their study reported increased FAS activity after sucrose administration and normalized FAS activity after FOS supplementation [35].

In this study, findings on percent liver cholesterol in the obese rats demonstrates that FOS supplementation reduced accumulation of triglycerides without particularly and significantly 
lowering percent liver cholesterol concentrations. This particular outcome is in contrast with several studies summarized by Beylot et al [37] that have reported modest liver cholesterol lowering effects by FOS supplementation [13]. However, these studies were conducted in different animal models and used cholesterol-rich diets supplemented with FOS [37]. Moreover, Lucas et al reports that high cholesterol diets have a direct effect on hepatic cholesterol concentrations [38]. Hence, differences in our study and the others can be best explained by variations in animal models, and in the regular rodent diet versus cholesterol-rich diets.

In addition to their effects on liver lipids, indigestible carbohydrates have previously been associated with modulation of blood lipids [35]. Previous studies with dietary supplementation of inulin or fructooligosaccharides in lean rats or hamsters resulted in decreases in serum triglyceridemia in both postprandial and fasted states [11, 13, 39, 40]. In fact, feeding male Wistar rats a diet supplemented with $10 \%$ oligofructose in the diet significantly lowers serum triacylglycerol concentrations [39]. Also, 10\% FOS (w/w) supplementation in high-fructose or high-sucrose diets for rodents and 10g/day in humans demonstrated lowered serum lipids when compared to controls [27, 41]. In this study, dietary supplementation at the level of 5\% FOS did not lower the TC, LDL-C and triglycerides in obese rats. Nevertheless, effects of FOS supplementation on plasma lipid profiles are inconclusive [37] demonstrating positive effects in short term but not long term studies [42]. For example, although indigestible fructans are known to modulate lipoproteins by decreasing LDL-C and increasing HDL-C in hypercholesterolemic humans [39], Fiordaliso and colleagues observed decreased esterified cholesterol and VLDL, but no changes in LDL and HDL cholesterol [39]. Moreover, decreased plasma cholesterol concentrations have not been observed in studies that supplemented FOS in the diets of lean and obese animal models $[11,13,35]$. Similarly FOS had no cholesterol lowering effects after $1 \%$ FOS (w/w) treatment in hypertriglyceridemic obese Beagle dogs [12]. Since FOS is hydrolyzed and absorbed as glucose and fructose [26], it is a mild enhancer of metabolic syndrome, and low concentrations used in this study and that of Frederique and others [12] may be ineffective in reversing advanced stages of hypertriglyceridemia found in obese animal models. The mechanisms by which FOS lowers plasma lipids are still under investigation. One proposed mechanism is through propionate inhibition of cholesterol synthesis [43]. The second proposed plasma cholesterol lowering mechanism is via inhibition of hepatic fatty acid synthase (FAS) activity [35]. Considering that this mechanism may be responsible for lower liver lipids observed in this study, it is probable that the livers of obese Zucker rats in our study secreted abnormal amounts of VLDL and TG hence countered the plasma lowering effects of FOS treatment. Obese Zucker rats have been reported to have an altered hepatic metabolism of free fatty acids resulting in hypersecretion of very low density lipoproteins [43].

Although this study did not observe significant changes in glucose control between treatment groups, the slight increase in HbAlc in O-FOS rats compared to the O-CTRL may be adequately explained by the absorbable amounts of sugars from the FOS treatment over the study period. As a matter of fact, Molis et al., report that a small fraction of ingested FOS is 
hydrolyzed during passage through the gastrointestinal tract and absorbed as glucose and fructose [26].

In this study, we also investigated the effect of FOS on relative PPAR- $\gamma$ gene expression in the abdominal white adipose tissue. Since obesity is associated with increased inflammatory cytokines such as interleukin (IL)-1, interleukin (IL)-6, and TNF- $\alpha$, which are antagonists of PPAR- $\gamma$, the expression of PPAR- $\gamma$ is decreased in obese rats [44]. PPAR- $\gamma$ is a master regulator of lipid and lipoprotein metabolism, energy homeostasis, and anti-inflammation factors. Therefore, it is highly expressed in adipose tissue and in the intestines where it enhances glucose homeostasis, triggers cellular differentiation, and promotes lipid storage [5]. Some natural PPAR- $\gamma$ modulators such as conjugated linoleic acid can increase PPAR- $\gamma$ expression resulting in improved insulin balance and glucose tolerance. Although not a ligand of PPAR- $\gamma$, dietary conjugated linoleic acid can increase the expression of PPAR- $\gamma$, adiponectin, and PPAR- $\gamma$ target genes in white adipose tissue of obese rats [45]. Adiponectin is an adipo-cytokine produced in adipose tissue and functions as an enhancer of insulin action, hence protects against insulin resistance [3]. Although PPAR- $\gamma$ activation contributes improvement in insulin sensitivity, our findings demonstrate that FOS is not a PPAR- $\gamma$ modulator in white adipose tissue of Zucker rats hence no evidence such a mechanism is presented.

\section{Conclusion:}

We conclude that the dietary FOS supplementation at the level of 5\% (w/w) may reduce hepatic steatosis and the risk for non-alcoholic fatty liver disease (NAFLD) associated with insulin resistance. However, dietary supplementation of FOS did not improve serum lipid profiles and glucose levels.

Abbreviations: PPAR- $\gamma$ : peroxisome proliferator-activated receptor- $\gamma$, L-CTRL $=$ Lean + control diet, O$\mathrm{CTRL}=$ Obese + control diet, O-FOS $=$ Obese + fructooligosaccharide $5 \%(\mathrm{w} / \mathrm{w})$.

\section{Competing interests:}

No competing financial or non-financial interests exist.

\section{Authors' contributions:}

Lydia Kaume was involved in the study design, interpretation of data and data analysis and wrote the manuscript. William Gilbert was involved in the study design, interpretation of data, and carried out the immunoassays. Vidya Gadang carried out the molecular genetic studies and was involved in drafting the manuscript. Latha Devareddy was responsible for the study design, coordination of data collection and analysis, and writing the grant proposal and significantly reviewing the manuscript. All authors have read and approved the final manuscript

\section{Acknowledgements:}


This study was funded by the Institute of Food Science and Engineering, University of Arkansas, Division of Agriculture. Fructooligosaccharides used in this study were provided by NutraFlora GTC Nutrition, Golden CO.

\section{References}

1. Kelly T, Yang W, Chen CS, Reynolds K, He J: Global burden of obesity in 2005 and projections to 2030. Int J Obes 2008, 32:1431-1437.

2. National Center for Health Statistics. Prevalence of Overweight and Obesity Among Adults:United States, 2003-2004. [http://www.cdc.gov/nchs/products/pubs/pubd/hestats/overweight/overwght_adult_03.htm].

3. Fava F, Lovegrove JA, Tuohy KM, Gibson GR: The potential role of the intestinal gut microbiota in obesity and the metabolic syndrome. Food Science \& Technology Bulletin: Functional Foods 2009, 5:71-92.

4. Kahn BB, Flier JS: Obesity and insulin resistance. J Clin Invest 2000, 106:473-481.

5. Torra IP, Chinetti G, Duval C, Fruchart JC, Staels B: Peroxisome proliferator-activated receptors: from transcriptional control to clinical practice. Curr Opin Lipidol 2001, 12:245.

6. Jenkins DJA, Kendall CWC, McKeown-Eyssen G, Josse RG, Silverberg J, Booth GL, Vidgen E, Josse AR, Nguyen TH, Corrigan S: Effect of a low-glycemic index or a highcereal fiber diet on type 2 diabetes: a randomized trial. JAMA 2008, 300:2742-2753.

7. Sung H, Choi Y, Cho S, Yun J: Fructooligosaccharides alter profiles of fecal short-chain fatty acids and bile acids in rats. Food Sc Biotech 2006, 15:51-56.

8. Swanson KS, Grieshop CM, Flickinger EA, Bauer LL, Chow JM, Wolf BW, Garleb KA, Fahey GC: Fructooligosaccharides and Lactobacillus acidophilus Modify Gut Microbial Populations, Total Tract Nutrient Digestibilities and Fecal Protein Catabolite Concentrations in Healthy Adult Dogs 1. J Nutr 2002, 132:3721-3731.

9. Bornet FRJ, Brouns F, Tashiro Y, Duvillier V: Nutritional aspects of short-chain fructooligosaccharides: natural occurrence, chemistry, physiology and health implications. Dig Liv Dis 2002, 34:111-120.

10. Alles MS, De Roos NM, Bakx JC, Van de Lisdonk E, Zock PL, Hautvast J: Consumption of fructooligosaccharides does not favorably affect blood glucose and serum lipid concentrations in patients with type 2 diabetes. Am J Clin Nutr 1999, 69:64-69.

11. Delzenne NM, Kok N, Fiordaliso MF, Deboyser DM, Goethals FM, Roberfroid MB: Dietary fructooligosaccharides modify lipid metabolism in rats. Am J Clin Nutr 1993, 57:820-820.

12. Frederique R, Swanson KS, Belsito KR, Vester BM, Wagner A, Istasse L, Diez M: ShortChain Fructooligosaccharides Influence Insulin Sensitivity and Gene Expression of Fat Tissue in Obese Dogs. J Nutr 2008, 138:1712-1718. 
13. Kok NN, Taper HS, Delzenne NM: Oligofructose modulates lipid metabolism alterations induced by a fat-rich diet in rats. $J$ Appl Toxicol 1998, 18:

14. Jurgoński A, Juśkiewicz J, Zduńczyk Z: Comparative effects of different dietary levels of cellulose and fructooligosaccharides on fermenta-tive processes in the caecum of rats. Journal of Animal and Feed Sciences 2008, 17:88-99.

15. Delzenne NM, Kok N: Effects of fructans-type prebiotics on lipid metabolism. Am J Clin Nutr 2001, 73:456S.

16. Cani PD, Neyrinck AM, Maton N, Delzenne NM: Oligofructose Promotes Satiety in Rats Fed a High-Fat Diet: Involvement of Glucagon-Like Peptide-1\&ast; \&ast. Obesity 2005, 13:1000-1007.

17. Ditschuneit HH, Flechtner-Mors M, Johnson TD, Adler G: Metabolic and weight-loss effects of a long-term dietary intervention in obese patients. Am J Clin Nutr 1999, 69:198.

18. Williams CM, Jackson KG: Inulin and oligofructose: effects on lipid metabolism from human studies. Br J Nutr 2007, 87:261-264.

19. Folch J, Lees M, Stanley G: A simple method for total lipid-extraction and purification. $J$ Biol Chem 1957, 226:497-509.

20. Searcy RL, Bergquist LM, Jung RC: Rapid ultramicro estimation of serum total cholesterol. The Journal of Lipid Research 1960, 1:349-351.

21. Schiffrin EJ, Blum S: Interactions between the microbiota and the intestinal mucosa. Eur J Clin Nutr 2002, 56 Suppl 3:S60-4.

22. Losada MA, Olleros T: Towards a healthier diet for the colon: the influence of fructooligosaccharides and lactobacilli on intestinal health. Nutr Res 2002, 22:71-84.

23. Devareddy L, Khalil AD, Korlagunta K, Hooshmand S, Bellmer DD, Bahram HA: The effects of fructo-oligosaccharides in combination with soy protein on bone in osteopenic ovariectomized rats. The Journal of The North American Menopause Society 2006, 13:692-699.

24. Ohta A, Ohtsuki M, Baba S, Takizawa T, Adachi T, Kimura S: Effects of fructooligosaccharides on the absorption of iron, calcium and magnesium in irondeficient anemic rats. J Nutr Sci Vitaminol 1995, 41:281-291.

25. Oku T, Tokunaga T, Hosoya N: Nondigestibility of a new sweetener, "Neosugar," in the rat. J Nutr 1984, 114:1574-1581.

26. Molis C, Flourie B, Ouarne F, Gailing MF, Lartigue S, Guibert A, Bornet F, Galmiche JP: Digestion, excretion, and energy value of fructooligosaccharides in healthy humans. Am J Clin Nutr 1996, 64:324-328.

27. Giacco R, Clemente G, Luongo D, Lasorella G, Fiume I, Brouns F, Bornet F, Patti L, Cipriano P, Rivellese AA: Effects of short-chain fructo-oligosaccharides on glucose and lipid metabolism in mild hypercholesterolaemic individuals. Ciin Nutr 2004, 23:331-340. 
28. Daubioul C, Rousseau N, Demeure R, Gallez B, Taper H, Declerck B, Delzenne N: Dietary Fructans, but Not Cellulose, Decrease Triglyceride Accumulation in the Liver of Obese Zucker fa/fa Rats 1. J Nutr 2002, 132:967-973.

29. Daubioul CA, Taper HS, De Wispelaere LD, Delzenne NM: Dietary Oligofructose Lessens Hepatic Steatosis, but Does Not Prevent Hypertriglyceridemia in Obese Zucker Rats 1. J Nutr 2000, 130:1314-1319.

30. Marchesini G, Brizi M, Morselli-Labate AM, Bianchi G, Bugianesi E, McCullough AJ, Forlani G, Melchionda N: Association of nonalcoholic fatty liver disease with insulin resistance. Am J Med 1999, 107:450-455.

31. Chitturi S, Abeygunasekera S, Farrell GC, Holmes-Walker J, Hui JM, Fung C, Karim R, Lin R, Samarasinghe D, Liddle C: NASH and insulin resistance: insulin hypersecretion and specific association with the insulin resistance syndrome. Hepatology 2003, 35:373379.

32. Sanyal AJ, Campbell-Sargent C, Mirshahi F, Rizzo WB, Contos MJ, Sterling RK, Luketic VA, Shiffman ML, Clore JN: Nonalcoholic steatohepatitis: association of insulin resistance and mitochondrial abnormalities. Gastroenterology 2001, 120:1183-1192.

33. Samuel VT, Liu ZX, Qu X, Elder BD, Bilz S, Befroy D, Romanelli AJ, Shulman GI: Mechanism of hepatic insulin resistance in non-alcoholic fatty liver disease. $J$ Biol Chem 2004, 279:32345-32359.

34. Korenblat KM, Fabbrini E, Mohammed BS, Klein S: Liver, muscle, and adipose tissue insulin action is directly related to intrahepatic triglyceride content in obese subjects. Gastroenterology 2008, 134:1369-1375.

35. Agheli N, Kabir M, Berni-Canani S, Petitjean E, Boussairi A, Luo J, Bornet F, Slama G, Rizkalla SW: Plasma lipids and fatty acid synthase activity are regulated by short-chain fructo-oligosaccharides in sucrose-fed insulin-resistant rats. J Nutr 1998, 128:1283.

36. Katsurada A, Iritani N, FUKUDA H, Matsumura Y, Nishimoto N, Noguchi T, Tanaka T: Effects of nutrients and hormones on transcriptional and post-transcriptional regulation of fatty acid synthase in rat liver. Eur J Biochem 1990, 190:427-433.

37. Beylot M: Effects of inulin-type fructans on lipid metabolism in man and in animal models. Br J Nutr 2005, 93:163-168.

38. Lucas EA, Lightfoot SA, Hammond LJ, Devareddy L, Khalil DA, Daggy BP, Smith BJ, Westcott N, Mocanu V, Soung DY: Flaxseed reduces plasma cholesterol and atherosclerotic lesion formation in ovariectomized Golden Syrian hamsters. Atherosclerosis 2004, 173:223-229.

39. Fiordaliso M, Kok N, Desager JP, Goethals F, Deboyser D, Roberfroid M, Delzenne N: Dietary oligofructose lowers triglycerides, phospholipids and cholesterol in serum and very low density lipoproteins of rats. Lipids 1995, 30:163-167. 
40. Trautwein EA, Rieckhoff D, Erbersdobler HF: Dietary inulin lowers plasma cholesterol and triacylglycerol and alters biliary bile acid profile in hamsters. $J$ Nutr 1998, 128:19371943.

41. Busserolles J, Gueux E, Rock E, Demigne C, Mazur A, Rayssiguier Y: Oligofructose protects against the hypertriglyceridemic and pro-oxidative effects of a high fructose diet in rats. $J$ Nutr 2003, 133:1903-1908.

42. Forcheron F, Beylot M: Long-term administration of inulin-type fructans has no significant lipid-lowering effect in normolipidemic humans. Metab Clin Exp 2007, 56:1093-1098.

43. Fukuda N, Azain MJ, Ontko JA: Altered hepatic metabolism of free fatty acids underlying hypersecretion of very low density lipoproteins in the genetically obese Zucker rats. J Biol Chem 1982, 257:14066-14072.

44. Chinetti G, Fruchart JC, Staels B: Peroxisome proliferator-activated receptors (PPARs): nuclear receptors at the crossroads between lipid metabolism and inflammation. Inflammation Res 2000, 49:497-505.

45. Zhou XR, Sun CH, Liu JR, Zhao D: Dietary conjugated linoleic acid increases PPAR [gamma] gene expression in adipose tissue of obese rat, and improves insulin resistance. Growth Hormone \& IGF Research 2008, 18:361-368. 